\title{
Total Parenteral Nutrition in the Newborn: Energy Substrates and Plasma Total Fatty Acids
}

\author{
MARJOLAIN PINEAULT, GUY LEPAGE, SUZANNE BISAILLON, CLAUDE C. ROY, AND \\ PHILIPPE CHESSEX \\ Perinatal Service and Research Center, Hôpital Sainte-Justine, Department of Pediatrics and Faculty of \\ Pharmacy, University of Montreal, Montreal, Quebec, Canada
}

\begin{abstract}
Carbohydrate and lipid intakes have both been found to modulate the metabolism of long-chain fatty acids. To define the respective infuence of these two energy substrates on plasma fatty acid concentrations, 32 studies were performed in 16 parenterally fed newborn infants (mean \pm SEM, birth wt: $2.15 \pm 0.1 \mathrm{~kg}$, age: $10 \pm 1 \mathrm{~d}$ ). In a paired cross-over design, the infants received for a given level of energy (60 versus $80 \mathrm{kcal} / \mathrm{kg} / \mathrm{d}$ ) two 6-d isonitrogenous and isocaloric regimens constructed so that the level of fat intake, 1 or $3 \mathrm{~g} / \mathrm{kg} / \mathrm{d}$ varied inversely with that of glucose. Total plasma fatty acid levels did not reflect the composition of the emulsion and varied with energy substrates. Plasma levels of three fatty acids rose inversely to the lipid intake, during the high glucose regimen: 16:1w7, 20:3w9 biologic markers of essential fatty acid deficiency, and 20:3w6 a derivative of 18:2w6. Glucose intake could exert its influence on 20:3w9 and 20:3w6 via insulin, an activator of $\Delta 6$ desaturase. Both glucose and fat should be taken into account when evaluating plasma fatty acid profile. (Pediatr Res 26:290-293, 1989)
\end{abstract}

Abbreviations

EFA, essential fatty acid

EFAD, essential fatty acid deficiency

$\mathrm{HF}$, high fat regimen

LF, low fat regimen

LIP, lipid emulsion

NEFA, non esterified fatty acid

PUFA, polyunsaturated fatty acid

TFA, total fatty acid

TG, triglyceride

Premature newborn infants have relatively low fat stores (1). Within a few days on a fat free diet, they can develop EFAD (2). Furthermore, they face a relative inability to handle intravenous fat intake due to their enzymatic immaturity, notably in lipoprotein lipase and lecithin cholesterol-acyl-transferase (3). To support a rapid growth rate, they require high energy regimens consisting of balanced glucose and fat intakes (4). Brain growth is a metabolic priority for the newborn (5), which depends on an adequate supply of nutrients for energy and structural purposes.

Received November 28, 1988; accepted May 22, 1989.

Correspondence and reprints requests Philippe Chessex, M.D., Research Center, Hôpital Sainte-Justine, 3175 Côte Sainte-Catherine, Montreal, Quebec H3T 1C5, Canada.

Supported by the Medical Research Council of Canada (MA-8664), and by a grant-in-aid from Travenol Canada Inc. (Mississauga, Ontario), and Pharmacia Canada Inc. (Dorval, Quebec). M.P. held a fellowship of the Interservice Clubs Council of Montreal.
Dietary fatty acids can be converted into long-chain polyunsaturated derivatives and incorporated in structural lipids (6). Modulators of long-chain fatty acids metabolism (7), as well as the low activity of the neonatal desaturase system $(8,9)$, could affect the metabolism of infused fatty acids during parenteral nutrition. Many factors have been reported to influence this enzyme complex. For example, EFAD, protein intake, and insulin activate the system, whereas the intake of either EFA or carbohydrates, as well as fasting and epinephrine, act as inhibitors (7).

In the course of an ongoing study aimed at defining the optimal proportion of glucose and fat in parenterally fed newborn infants, the effect of different glucose/fat ratios on plasma fatty acids was evaluated.

\section{MATERIALS AND METHODS}

The study population, experimental design and intravenous regimens, have been previously described (10). Sixteen appropriate for gestational age newborn infants (mean \pm SEM, birth wt: $2150 \pm 115 \mathrm{~g}$, age: $10 \pm 1 \mathrm{~d}$ ), were studied in two Latin square cross-over designs under regimens providing either 60 or $80 \mathrm{kcal} /$ $\mathrm{kg} / \mathrm{d}$ (Fig. 1). Indications for intravenous nutritional support were as follows: necrotizing enterocolitis $(n=7)$, gastroschisis ( $n$ $=4)$, esophageal atresia $(n=2)$, duodenal atresia $(n=2)$, intolerance for oral feedings $(n=1)$. In a cross-over fashion, the infants were studied for a given energy intake, over two 6-d isonitrogenous regimens $(450 \mathrm{mg} / \mathrm{kg} / \mathrm{d}$ of nitrogen) differing by the level of fat intake: LF $(1 \mathrm{~g} / \mathrm{kg} / \mathrm{d})$ and $\mathrm{HF}(3 \mathrm{~g} / \mathrm{kg} / \mathrm{d})$. These specific fat intakes were chosen to cover EFA requirements and to avoid hypertriglyceridemia. The infused glucose varied inversely with the lipid intake in order to keep the regimens isocaloric (Table 1). To control for the effect of sequence (starting the protocol with LF or HF), half of the patients began with LF (Fig. 1). In this experimental design unpaired comparisons allowed for the evaluation of the respective influence of glucose and fat. The constancy of the infusion rates was assured by an infusion pump for the amino acid-dextrose solution (Travasol $10 \%$ blend C, Travenol Laboratories Inc., Deerfield, IL) and a syringe pump for the lipid emulsion (Nutralipid 10\%, Pharmacia, Dorval, Quebec, Canada). Blood sampling was done on the 5th day of each period, at steady state (continuous infusion) distal to the infusion site (11). NEFA and TFA were determined on capillary column by gas chromatography following specific methylation (12) and direct transesterification (13), respectively, on $100 \mu \mathrm{L}$ of plasma. Plasma fat emulsion and TG levels were determined as described previously (10). Approval by the Hospital Human Ethics Committee and parental consent were obtained before the investigation.

Population size different than eight was due to nonavailability of plasma. In one patient, 20:5w3 was not detectable at $60 \mathrm{kcal} /$ $\mathrm{kg} / \mathrm{d}$, for analytical purposes. The data were evaluated by 
ANOVA for repeated and independent measures. In the case of heterogeneity of variances a $t$ test on the mean of the differences was performed for paired data and a Welch $t$ test (14) for unpaired results. The level of significance was set at 0.05 .

\section{RESULTS}

The macronutrient intakes are presented in Table 1 . The fatty acid composition of the fat emulsion is shown in Table 2. The metabolic response to lipid infusions was monitored by plasma level of the fat emulsion, TG (10), and fatty acids; values were within normal ranges $(15,16)$. Despite the tight linear correlation between the plasma levels of fat emulsion (LIP, g/L) and TG $(\mathrm{mmol} / \mathrm{L})(\mathrm{TG}=0.85 \mathrm{LIP}+0.05, r=0.86, p<0.001, n=19)$ the dispersion was important (SE: $0.27 \mathrm{mmol} / \mathrm{L}$ ) confirming that

n

4

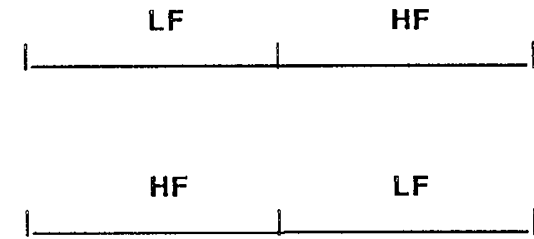

4

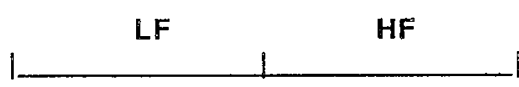

$80 \mathrm{kcal} / \mathrm{kg} / \mathrm{d}$

4

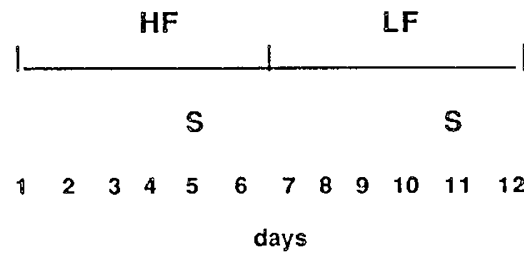

Fig. 1. The experimental design was a Latin square cross-over. For a given level of energy ( 60 or $80 \mathrm{kcal} / \mathrm{kg} / \mathrm{d})$ the infants served as their own control for two 6-d periods $\left(\mathrm{P}_{1}\right.$ and $\left.\mathrm{P}_{2}\right)$ of isonitrogenous infusions differing only by the source of calories: HF and LF. To allow for the evaluation of the sequence of administration, half of the patients started with the high fat regimen. Blood sampling $(S)$ was performed on the 5 th $\mathrm{d}$ of each period.
TG could not be reliably predicted from nephelometry (17). However, with plasma fat emulsion levels $<1.5 \mathrm{~g} / \mathrm{L}, \mathrm{TG}$ values were lower than the suggested upper limit of $1.7 \mathrm{mmol} / \mathrm{L}(18)$. NEFA (LF: $776 \pm 65$ versus HF: $1584 \pm 145 \mu \mathrm{mol} / \mathrm{L}, n=16$ ) and TFA (LF: $7025 \pm 404$ versus HF: $13137 \pm 571 \mu \mathrm{mol} / \mathrm{L}, n$ $=13$ ) rose significantly with intake.

Plasma levels of individual fatty acids are reported as absolute values $(\mu \mathrm{mol} / \mathrm{L})$ as well as percent of total fatty acids (Table 3 ), which could lead to wide differences in data interpretation. For instance the significant drop in percent of 20:4w6 during $\mathrm{HF}$ regimens is in keeping with previously published data expressed in percent of TFA (19), but is in contradiction with absolute values expressed in $\mu \mathrm{mol} / \mathrm{L}$; the same holds true for $24: 1 \mathrm{w} 9$ at $60 \mathrm{kcal} / \mathrm{kg} / \mathrm{d}$. We considered absolute values as they reflect more closely the metabolic activities than percentages; levels expressed in percent are also more sensitive to the dilutional effect of the lipid infusion.

Plasma levels of infused fatty acids rose significantly with the increased lipid intake of the HF regimens (Table 3 ). Conversely, three derivatives of infused fatty acids in the emulsion, namely 16:1w7, 20:3w9, 20:3w6, rose with the LF regimens (Table 3). For a given level of fat intake increasing the glucose intake in an unpaired fashion (HF 60 versus $\mathrm{HF} 80 \mathrm{kcal} / \mathrm{kg} / \mathrm{d}$ ) had a significant effect on 20:3w9. But for a given glucose intake of $11 \mathrm{~g} / \mathrm{kg} /$ $\mathrm{d}$, increasing the fat intake from LF $60 \mathrm{kcal} / \mathrm{kg} / \mathrm{d}$ to $\mathrm{HF} 80 \mathrm{kcal} /$ $\mathrm{kg} / \mathrm{d}$ produced a significant drop in plasma levels of $16: 1 \mathrm{w} 7$ (Table 3).

The Mead acid/arachidonic acid (20:3w9/20:4w6) ratio $>0.025$ has been used to biochemically characterize EFAD (20). This ratio decreased significantly with the $\mathrm{HF}$ regimens $(60 \mathrm{kcal} /$ $\mathrm{kg} / \mathrm{d}, \mathrm{LF}: 0.012 \pm 0.001$ versus $\mathrm{HF}: 0.007 \pm 0.004, n=6, p<$ $0.05 ; 80 \mathrm{kcal} / \mathrm{kg} / \mathrm{d}, \mathrm{LF}: 0.036 \pm 0.008$ versus HF: $0.015 \pm 0.002$, $n=7, p<0.05)$. But with a constant LF intake, the Mead acid/ arachidonic acid ratio increased significantly at the higher energy level; the difference in energy intake being achieved by an increased glucose intake. There was no effect of glucose intake on plasma TG, NEFA, TFA, and w6 and w3 PUFA concentrations.

\section{DISCUSSION}

Parenterally fed newborn infants exhibited a good tolerance to fat intakes, varying from 1 to $3 \mathrm{~g} / \mathrm{kg} / \mathrm{d}$, as circulating lipid levels were within normal ranges. While on continuous infusion, the plasma TFA did not reflect the composition of the emulsion. Changes in intravenous diet resulted in TFA patterns not proportionally related to the dose of fatty acids infused.

This discrepancy between the rate of infusion and the plasma levels was most striking for 16:1w7, 20:3w9, and 20:3w6, three derivatives that rose during the LF regimens (Table 3). Elevated

Table 1. Parenteral intakes* of paired isocaloric and isonitrogenous regimens differing by source of nonprotein energy $(L F, H F) \dagger$

\begin{tabular}{|c|c|c|c|c|}
\hline & \multicolumn{2}{|c|}{$\begin{array}{c}60 \mathrm{kcal} / \mathrm{kg} / \mathrm{d} \\
(n=8)\end{array}$} & \multicolumn{2}{|c|}{$\begin{array}{c}80 \mathrm{kcal} / \mathrm{kg} / \mathrm{d} \\
(n=8)\end{array}$} \\
\hline & LF & $\mathrm{HF}$ & LF & $\mathrm{HF}$ \\
\hline Amino acids $(\mathrm{g} / \mathrm{kg} / \mathrm{d})$ & $2.6 \pm 0.1$ & $2.6 \pm 0.1$ & $2.6 \pm 0.1$ & $2.6 \pm 0.1$ \\
\hline Glucose $(\mathrm{g} / \mathrm{kg} / \mathrm{d})$ & $10.9 \pm 0.3$ & $5.4 \pm 0.2$ & $15.6 \pm 0.2$ & $11.1 \pm 0.3$ \\
\hline Lipid $(g / k g / d)$ & $1.04 \pm 0.02$ & $2.75 \pm 0.08$ & $1.02 \pm 0.05$ & $2.81 \pm 0.05$ \\
\hline$\%$ of nonprotein energy as lipid & $24 \pm 1$ & $62 \pm 1$ & $17 \pm 1$ & $46 \pm 1$ \\
\hline
\end{tabular}

* Values represent mean \pm SEM.

$\dagger$ For the sake of clarity Table 1 does not show the cross-over between LF and HF, in which half of the studies started by HF. 
Table 2. Fatty acid composition of parenteral emulsion, nutralipid 10\%, expressed as absolute value, and as \% of total fatty acids (mean \pm SEM)

\begin{tabular}{lrc}
\hline Fatty acids & $\mu \mathrm{mol} / \mathrm{dL}$ & \% of TFA \\
\hline $16: 0$ & 4489 & 12 \\
$18: 0$ & 1621 & 4.33 \\
$16: 1 \mathrm{w} 7$ & 50 & 0.13 \\
$18: 1 \mathrm{w} 7$ & 473 & 1.26 \\
$18: 1 \mathrm{w} 9$ & 6569 & 17.55 \\
$18: 2 \mathrm{w} 6$ & 19710 & 52.67 \\
$18: 3 \mathrm{w} 6$ & 133 & 0.36 \\
$20: 3 \mathrm{w} 6$ & 174 & 0.47 \\
$20: 4 \mathrm{w} 6$ & 116 & 0.31 \\
$18: 3 \mathrm{w} 3$ & 3557 & 9.51 \\
$22: 6 \mathrm{w} 3$ & 416 & 1.1 \\
Others & $<80$ & $<0.25$ \\
TFA & 37419 & \\
\hline
\end{tabular}

Table 3. Plasma fatty acid concentration (mean \pm SEM) expressed as absolute value $(\mu \mathrm{mol} / L)$ and as \% of total fatty acid $(\%)$

\begin{tabular}{|c|c|c|c|c|}
\hline & \multicolumn{2}{|c|}{$60 \mathrm{kcal}$} & \multicolumn{2}{|c|}{$80 \mathrm{kcal}$} \\
\hline & $\mathrm{LF}^{*}$ & $\mathrm{HF}$ & LF & $\mathrm{HF}$ \\
\hline $16: 0$ & $\begin{array}{c}2163 \pm 175 \\
(28.42 \pm 0.52)\end{array}$ & $\begin{array}{r}3919 \pm 126 \dagger \\
(27.43 \pm 0.68)\end{array}$ & $\begin{array}{c}1819 \pm 141 \\
(27.53 \pm 0.88)\end{array}$ & $\begin{array}{r}3261 \pm 268 \dagger \\
(26.59 \pm 0.39)\end{array}$ \\
\hline
\end{tabular}

$\begin{array}{ccccc}18: 0 & 676 \pm 53 & 1379 \pm 49 \dagger & 608 \pm 53 & 1207 \pm 114 \dagger \\ & (8.9 \pm 0.32) & (9.67 \pm 0.35) & (9.32 \pm 0.22) & (9.8 \pm 0.26)\end{array}$

$\begin{array}{ccccc}16: 1 w 7 & 218 \pm 29 & 141 \pm 12 \dagger & 177 \pm 22 & 111 \pm 11 \dagger \\ & (2.83 \pm 0.25) & (0.99 \pm 0.08) & (2.70 \pm 0.26) & (0.91 \pm 0.06) \dagger\end{array}$

$18: 1$ w $91653 \pm 118 \quad 3202 \pm 33 \dagger \quad 1338 \pm 134 \quad 2654 \pm 278 \dagger$ $(21.95 \pm 1.03)(22.44 \pm 0.13) \quad(20.32 \pm 0.63) \quad(21.4 \pm 0.60)$
$20: 3 w 9 \quad 6.3 \pm 1.8 \quad 3.9 \pm 0.4 \quad 16.1 \pm 5.1 \quad 8.8 \pm 1.8 \dagger$ $\begin{array}{llll}(0.08 \pm 0.02) & (0.03 \pm 0.003) \dagger(0.26 \pm 0.08) & (0.07 \pm 0.02)\end{array}$

24:1w9 $54.2 \pm 7.1 \quad 72.4 \pm 4.0 \dagger \quad 61.4 \pm 5.7 \quad 81.5 \pm 6.4 \dagger$ $\begin{array}{llll}(0.70 \pm 0.06) & (0.51 \pm 0.03) \dagger \quad(0.96 \pm 0.09) & (0.67 \pm 0.04)\end{array}$

$18: 2 w 6 \quad 1772 \pm 85 \quad 3991 \pm 145 \dagger \quad 1443 \pm 176 \quad 3285 \pm 268 \dagger$ $(23.64 \pm 0.86)(27.96 \pm 0.92) \dagger \quad(21.6 \pm 1.13)(26.76 \pm 0.82) \dagger$
$20: 3 w 6 \quad 98.9 \pm 12.0 \quad 69.3 \pm 3.2 \dagger$ $(1.30 \pm 0.12)(0.49 \pm 0.03) \dagger$
$107 \pm 11.7 \quad 84.8 \pm 8.2 \dagger$
$(1.66 \pm 0.12)(0.70 \pm 0.07) \dagger$

$\begin{array}{ccc}20: 4 w 6 & 470 \pm 79 & 573 \pm 51 \\ & (5.97 \pm 0.70) & (4.03 \pm 0.37) \dagger\end{array}$

$407 \pm 40 \quad 539 \pm 34$

$(6.37 \pm 0.57)(4.49 \pm 0.32) \dagger$

$\begin{array}{ccccc}18: 3 w 33 & 101 \pm 8.8 & 283 \pm 25 \dagger & 82 \pm 15 & 230 \pm 30 \dagger \\ & (1.33 \pm 0.05) & (1.99 \pm 0.17) \dagger & (1.21 \pm 0.14) & (1.85 \pm 0.18) \dagger \\ & & & & \\ 20: 5 w 3 & 21.7 \pm 5.7 & 25.8 \pm 3.3 & 30.3 \pm 3.8 & 34.8 \pm 3.6 \\ & (0.28 \pm 0.07) & (0.18 \pm 0.02) & (0.48 \pm 0.07) & (0.3 \pm 0.04) \dagger \\ & & & & \\ 22: 6 w 3 & 177 \pm 13 & 406 \pm 19 \dagger & 172 \pm 12 & 398 \pm 24 \dagger \\ & (2.34 \pm 0.06) & (2.84 \pm 0.12) \dagger & (2.67 \pm 0.12) & (3.31 \pm 0.19) \dagger\end{array}$

\begin{tabular}{|c|c|c|}
\hline \multicolumn{2}{|l|}{$T F$} & $14273 \pm 195 \dagger$ \\
\hline
\end{tabular}

* Half of the studies started by HF.

$\dagger p<0.05$ for comparison between LF and HF at a given level of energy intake. At $60 \mathrm{kcal}, n=6$ except for 20:5w3 $(n=5)$; at $80 \mathrm{kcal}, n$ $=7$. levels of 16:1w7 and 20:3w9 have been proposed as biologic markers of EFAD (20). It is surprising that despite the continuous lipid infusion these markers would be found in plasma after only 9 to $21 \mathrm{~d}$ on a low lipid intake [age at study (10) plus 5 days on LF regimens].

The periods of lipid infusion (LF, HF) of our study were relatively short compared to membrane phospholipid fatty acid turnover (21). However, Farrell et al. (22) recently suggested that, in the premature infant, tissue linoleate responded as early as 7 d to exogenous fat intake. Although plasma phospholipids or cholesterol esters might have been a better indicator of the effect of diet on endogenous fat metabolism (23), others (24) found that lipid fractionation does not provide additional information to justify the extra step. This procedure requires more blood and is also time consuming. Furthermore, Lepage et al. (25) found that the plasma total fatty acid pattern was representative of phospholipid red blood cells and platelets fatty acid profiles in EFA deficient children with cystic fibrosis.

Monitoring of plasma lipids is most frequently performed after interruption of the infusion because of the concern that infused TG might change plasma ratios of endogenous and exogenous fatty acids. Therefore plasma levels of fatty acids infused in large amounts such as 18:2w6, cannot be interpreted. However, even in hyperlipemic patients, the total plasma fatty acid pattern was shown to provide a reliable assessment of EFA status (26). In our study, despite the continuous lipid intake, 20:3w9, a noninfused fatty acid, increased during the LF regimen. As in the study from Farrell et al. (22), premature infants on a fat free or low fat diet rapidly showed elevated plasma levels of 20:3w9 accompanied by normal levels of 20:4w6. This fatty acid profile seems to be characteristic for this population early after birth. The provision of an adequate linoleic acid intake promptly corrected the deficient state in plasma and tissue (22), as in newborn infants tissue response to changes in dietary fat profile is very rapid compared to adults (27). It remains to be demonstrated whether these changes in specific plasma fatty acids are an early indication of EFAD.

Provision of linoleic acid representing $4 \%$ of total energy intake has been recommended to cover essential fatty acid requirements in the newborn $(28,29)$. More recently Farrell et al. $(22)$ recommended even larger amounts of linoleic acid $(1.19 \mathrm{~g} / \mathrm{kg} / \mathrm{d})$ for premature infants. The present protocol provided a minimum of $1 \mathrm{~g} / \mathrm{kg} / \mathrm{d}$ of soy bean oil emulsion, or 8 to $10 \%$ of energy as $18: 2 \mathrm{w} 6$. Mead acid/arachidonic acid (20:3w9/20:4w6) ratio is a widely used index of EFAD. The highest ratios were found during the low fat intakes. Noteworthy is that with the LF $80 \mathrm{kcal}$ regimen this ratio was in a range associated by Siguel et al. (2) with EFAD. For a given low fat intake, the ratio was significantly greater at $L F 80$ than at $L F 60 \mathrm{kcal} / \mathrm{kg} / \mathrm{d}$, suggesting an influence of glucose or insulin. However, the interpretation of this ratio can be misleading; only the variations in the numerator 20:3w9 were responsible for these results because the arachidonic acid levels remained normal, as reported by others (22).

Among the dietary, environmental, and hormonal factors known to influence long-chain fatty acid metabolism glucose has been reported to exert an inhibitory effect, whereas insulin is an activator of the $\Delta 6$ desaturase (30). Despite the wide range of glucose intakes $(5$ to $17 \mathrm{~g} / \mathrm{kg} / \mathrm{d}$ ) the infants remained remarkably normoglycemic, but insulinemia rose significantly $(8.6 \pm 1.0$ to $14.5 \pm 1.5 \mu \mathrm{U} / \mathrm{mL}$ ) when changing from the 60 to $80 \mathrm{kcal} / \mathrm{kg} / \mathrm{d}$ energy intakes (10). The increase in circulating insulin levels could explain the statistically significant influence of glucose intake on the levels of 20:3w9. The insulin-induced increase in $\triangle 6 \mathrm{D}$ activity could also account for the trend toward higher plasma levels of $20: 3 \mathrm{w} 6$ and $20: 5 \mathrm{w} 3$ found at $80 \mathrm{kcal} / \mathrm{kg} / \mathrm{d}$ despite constant lipid intakes (Table 3). In contrast to studies measuring the effect of glucose during refeeding of fasted rats (31) or after a glucose-rich diet (32), our observations were made in patients receiving carbohydrates at commonly used levels of intake. 
These results show that plasma total fatty acids are influenced by variations in both glucose and lipid intakes. With as little as $100 \mu \mathrm{L}$ of plasma, changes in uninfused PUFA can be detected as early as $5 \mathrm{~d}$ after switching energy substrates. In a study designed more specifically to document EFAD, it remains to be verified if circulating levels of $16: 1 \mathrm{w} 7$ and $20: 3 \mathrm{w} 9$ are early plasma indicators of later tissue deficiencies.

\section{REFERENCES}

1. Widdowson EM 1982 Importance of nutrition in development, with special reference to feeding low-birth-weight infants. In: Proceedings of the Second Ross Clinical Research Conference: Meeting Nutritional Goals for LowBirth-Weight Infants. Ross Laboratories, Columbus, $\mathrm{OH}$, pp 4-11

2. Cooke RJ, Zee P, Yeh YY 1984 Essential fatty acid status of the premature infant during short-term fat-free parenteral nutrition. J Pediatr Gastroenterol Nutr 3:446-449

3. Stahl GE, Spear ML, Hamosh M 1986 Intravenous administration of lipid emulsions to premature infants. Clin Perinatol 13:133-162

4. Georgieff MK, Sasanow SR 1986 Nutritional assessment of the neonate. Clin Perinatol 13:73-100

5. Winick M, Morgan BLG 1985 Nutrition and brain development. In: Walker WA, Watkins JB (eds) Nutrition in Pediatrics. Little, Brown and Company, Boston, pp 233-251

6. Weiner TW, Sprecher H 1984 Arachidonic acid, 5,8,11-eicosatrienoic acid and $5,8,11,14,17$-eicosapentaenoic acid. Dietary manipulation of the levels of these acids in rat liver and platelet phospholipids and their incorporation into human platelet lipids. Biochim Biophys Acta 792:293-303

7. Brenner RR 1981 Nutritional and hormonal factors influencing desaturation of essential fatty acids. Prog Lipid Res 20:41-47

8. Clandinin MT, Chappell JE, Heim T 1981 Do low weight infants require nutrition with chain elongation-desaturation products of essential fatty acids? Prog Lipid Res 20:901-904

9. Gil A, Saitúa, Cassorla X, Duque C, Uauy R 1984 Effects of postnatal age and diet on plasma lipids. Am J Clin Nutr 39:668

10. Pineault M, Chessex $P$, Bisaillon S, Brisson G 1988 Total parenteral nutrition in the newborn: impact of the quality of infused energy on nitrogen metabolism. Am J Clin Nutr 47:298-304

11. Pineault M, Chessex P, Bisaillon S, Lepage D, Dallaire L 1988 Total parenteral nutrition in the newborn. 2. Amino acids-energy interrelationships. Am $\mathbf{J}$ Clin Nutr 48:1065-1069

12. Lepage G, Roy CC 1988 Specific methylation of plasma non-esterified fatty acids in a one-step reaction. J Lipid Res 29:227-235

13. Lepage G, Roy CC 1986 Direct transesterification of all classes of lipids in a one-step reaction. J Lipid Res 27:114-120

14. Winer BJ 1962 Inference with respect to means and variance. In: Maytham W, Shapiro A, Stern J (eds). Statistical Principles in Experimental Design, 2nd ed. McGraw-Hill, New York, p 4-42

15. Kao L Cheng $\mathrm{MH}$, Warburton D 1984 Triglycerides, free fatty acids, free fatty acids-albumin molar ratio, and cholesterol levels in serum of neonates receiving long-term lipid infusions: controlled trial of continuous and intermittent regimens. J Pediatr 104:429-435

16. Andrew G, Chan G, Schiff D 1976 Lipid metabolism in the neonate. II. The effect of intralipid on bilirubin binding in vitro and in vivo. J Pediatr 88:279-284

17. Schreiner RL, Glick MR, Nordschow CD, Gresham EL 1979 An evaluation of methods to monitor infants receiving intravenous lipids. J Pediatr 94:197200

18. Paust H, Schröder H, Park W, Jakobs C, Frauendienst G 1983 Fat elimination in parenterally fed low birth weight infants during the first two weeks of life. JPEN 7:557-559

19. Friedman Z, Frolich JC 1979 Essential fatty acids and the major urinary metabolites of the $E$ prostaglandins in thriving neonates and in infants receiving parenteral fat emulsions. Pediatr Res 13:932-936

20. Siguel EN, Chee KM, Gong J, Schaefer EM 1987 Criteria for essential fatty acid deficiency in plasma as assessed by capillary column gas-liquid chromatography. Clin Chem 33:1869-1873

21. Crawford MA 1983 Background to essential fatty acids and their prostanoid derivatives. Br Med Bull 39:210-213

22. Farrell PH, Gutcher GR, Palta M, DeMets D 1988 Essential fatty acid deficiency in premature infants. Am J Clin Nutr 48:220-229

23. Holman RT 1986 Control of polyunsaturated acids in tissue lipids. J Am Coll Nutr 5:183-211

24. Siguel EN, Blumberg JF, Caesar J 1986 Monitoring the optimal infusion of intravenous lipids: detection of essential fatty acid deficiency. Arch Pathol Lab Med 110:792-797

25. Lepage G, Ronco N, Smith L, Galeano N, Levy E, Roy CC 1988 Are tissue lipids necessary to establish the diagnosis of EFA deficiency in CF? J Lipid Res (in press)

26. Lepage G Levy E Thibault L, Seidman E, Ronco N, Roy CC 1989 Essential fatty acid deficiency in GSD-I treated with a fat-free elemental formula. FASEB J 3:4170(abstr)

27. Sarda P, Lepage G, Roy CC, Chessex P 1987 Storage of medium-chain triglycerides in adipose tissue of orally fed infants. Am J Clin Nutr 45:399405

28. American Academy of Pediatrics. Committee on Nutrition 1985 Nutritional needs of low-birth-weight infants. Pediatrics 75:976-986

29. Committee on Nutrition of the Preterm Infant, European Society of Paediatric Gastroenterology and Nutrition 1987 Nutrition and feeding of preterm infants. Acta Paediatr Scand [Suppl] 336:1-14

30. Brenner RR 1977 Regulatory function of $\Delta 6$ desaturase-key enzyme of polyunsaturated fatty acid synthesis. Adv Exp Biol 83:85-101

31. Brenner RR, Peluffo RO, Mercuri O, Restelli MA 1968 Effect of arachidonic acid in the alloxan-diabetic rat. Am J Physiol 215:63-69

32. Peluffo RO, Gomez Dumm NT, Alanis MJ, Brenner RR 1971 Effect of protein and insulin on linoleic acid desaturation of normal and diabetic rats. J Nutr 101:1075-1084 